Doi: 10.21608/zumj.2019.16984.1519

Pediatric

ORIGINAL ARTICLE

\title{
Clinical Characterizations of Neonatal Admission in Neonatal Intensive Care Unit at Zagazig University Children Hospital
}

\author{
Ehab Abdel Moniem Elbanna ${ }^{1}$, Dina Tawfeek Sarhan ${ }^{1}$, Salah Elsayed Ibrahim ${ }^{2}$, Tarek Abd \\ EL Latef Abd EL Aziz ${ }^{1 *}$. \\ 1-Pediatric Department, Faculty of Medicine, Zagazig University, Sharkia, Egypt. \\ 2- Clinical pathology Department, Faculty of Medicine, Zagazig University, Sharkia, Egypt.
}

\section{Corresponding author:}

\section{Tarek Abd EL Latef Abd}

EL Aziz*

Clinical pathology

Department, Faculty of

Medicine, Zagazig

University, Sharkia, Egypt.

tareklatef43@gmail.com

\section{ABSTRACT}

Background: The neonatal intensive care unit (NICU) has high-quality medical staff and tools to care for premature and sick term neonates. Epidemiological information regarding diseases, management and outcome of admitted neonates in NICU are the basis for establishing an effective intervention and adjusting the quality of health care. This study aimed to determine disease patterns, prescribed medications, resource utilization and outcome of the neonates hospitalized in NICU. Methods: Observational cross-sectional study, which included 213 neonates admitted from May 2018 to January 2019, at NICUs of obstetric and children hospitals of Zagazig University. Perinatal and demographic data, diagnosis, prescribed medications and outcome were documented and analyzed. Results: The commonest primary diagnosis during NICU admission were RDS (21.1\%) followed by surgical problems $(14.6 \%)$, late onset sepsis (12.2\%), congenital pneumonia (8.5\%), early onset sepsis $(8 \%)$ and aspiration pneumonia $(5.2 \%)$.All of the studied neonates received antibiotics while $(97.1 \%)$ received parenteral nutrition ,(30.1\%) received positive inotropes and $(28.6 \%)$ received caffeine citrate. As regard the outcome, $(19.2 \%)$ of the studied neonates were died and the causes of neonatal deaths were sepsis $(12.2 \%)$ followed by respiratory failure $(5.1 \%)$, cardiogenic shock (2.8\%), surgical complications $(1.9 \%)$, inborn error of metabolism (IEM) $(1 \%)$ and severe hypoxic ischemic encephalopathy (HIE) $(0.5 \%)$. Conclusion: RDS and surgical diseases were the most common causes of NICU admission. The antibiotics and parenteral nutrition were prescribed frequently in NICU and sepsis was the main cause of newborn mortality.

Key words: NICU; neonatal admission; neonatal mortality; Sepsis

\section{INTRODUCTION}

E very newborn admitted to a NICU experiences the benefits of specialized care and is exposed to the associated hazards. [1]

The commonest primary diagnoses during admission to NICU were prematurity with respiratory diseases $(36.6 \%)$, septicemia $(22.7 \%)$, and perinatal asphyxia (16.2\%). and the remaining reasons for NICU admission were meconium aspiration syndrome $(13.9 \%)$, jaundice $(6.0 \%)$, and others (4.6\%). [2]
The mortality rate of newborn in Egypt in 2013 was (11.8 per 1000 live births), which accounted for almost $54 \%$ of deaths of children under the age of 5 years. [3]

Neonatal deaths are due to infections, prematurity and perinatal asphyxia but recrudescence of these deaths differ between NICUs. [4]

Data from NICUs about clinical presentation, prescribed medications, resource utilization and outcome of admitted neonates can provide us with solutions to discover how methods of medical care can lead to 
improvement in neonatal outcome because we cannot manage what we cannot measure. So, this study was done to detect the disease patterns and discharge status of the newborns hospitalized in NICU during nine months period.

\section{METHODS}

This observational cross-sectional study carried out at NICUs of both children and obstetric hospitals of Zagazig University, in a period between May 2018 and January 2019. Both hospitals are a reference for neonatal care and neonatal surgery, receiving high-risk pregnant women. The neonatology service has a capacity of 33 intensive care beds including the surgical unit and one nurse for every 5 beds in NICU.

The research protocol was approved by the Institutional review Board (IRB) of the faculty of medicine Zagazig University. Written informed consent was taken from the parents of enrolled newborns before being included in this study.

The Work was carried out in accordance with the code of Ethics of the World Medical Association (Declaration of Helsinki) for studies involving humans.

All newborns term and preterm, both inborn and out born that admitted during the study duration were included in this study. These neonates were categorized as inborn if delivered in Zagazig university obstetric hospital and as outborn if born outside. Newborn who died or discharged within 12 hours of admission, newborn who need only palliative care and neonates who left hospital against medical advice (LAMA) were excluded from this study. Jaundiced neonates admitted only for phototherapy treatment in our separate unit were also excluded from this study because these neonates were not incubated.

All newborns admitted in NICUs included in this study were subjected to the following: neonatal admission information in the form of (infant identification, date of birth, date of admission, gestational age and birth weight), mother/obstetric information in the form of (maternal age, antenatal history, obstetric complications, maternal diseases, drugs intake and type of delivery), careful clinical examination, management according to clinical conditions, daily resource utilization (entered daily) in the form of (respiratory support, nutritional support, IV lines, medications, blood transfusion and surgical procedures) and evaluation of neonatal outcome including the cause of mortality if died. The flow chart of this study is presented in (figure 1).

Statistical analysis:

Data collected through clinical history, examination findings, laboratory investigations and management were integrated into a master sheet using Microsoft excel software, and then they were coded and analyzed. The Data were then imported into SPSS (Statistical Package for the Social Sciences) software to be analyzed (SPSS version 20.0). The qualitative data were represented as number and percentage, while the quantitative continuous data were represented by mean $\pm \mathrm{SD}$.

\section{RESULTS}

The results of our study showed that the mean of gestational age of the studied group was $(35.3 \pm 2.7)$ weeks, the mean of neonatal age at admission was $(3.1 \pm 2.0)$ days and $(51.6 \%)$ of them were males. Preterm neonates were (55.9\%). According to birth weight, the mean of birth weight was $2300 \pm 900 \mathrm{gm}$ and $(42.7 \%)$ of neonates were $\geq 2500 \mathrm{gm}$. the demographic data of the studied group are presented in (table 1).

The mean of maternal age of the studied group was $(28.1 \pm 5.8)$ years, $(30.5 \%)$ were paragravida $3,(76.5 \%)$ didn't have chronic disease; antihypertensive drug (methyl dopa) was the commonest drug $(29.1 \%)$. The data are presented in (table 2).

Inborn neonates were $(83.1 \%)$ and outborn were $(16.9 \%),(82.2 \%)$ of neonates were born by cesarean section (C.S), low Apgar score followed by cord prolapse were the commonest complications of delivery $(9.4 \%$ $\& 8.5 \%$ respectively). The data are presented in (table 3).

The commonest diagnosis during NICU admission were RDS (21.1\%) followed by surgical problems (14.6\%), late onset sepsis $(12.2 \%)$, congenital pneumonia $(8.5 \%)$ early onset sepsis $(8 \%)$ and aspiration pneumonia $(5.2 \%)$. the data are presented in (Figure 2). 
All of the studied newborns received antibiotics while $(97.1 \%)$ received parenteral nutrition and, $(30.1 \%)$ received positive inotropes and $(28.6 \%)$ received caffeine citrate. $(15.5 \%)$ of the studied group had surgical problems and abdominal surgery was the commonest surgery done for these neonates $(9.9 \%)$. The data are presented in (table 4)
The results of this study showed that (19.2\%) of the studied newborns were died and $(80.8 \%)$ of the studied newborns were discharged and the commonest cause of mortality among the studied newborns was sepsis $(12.2 \%)$ followed by respiratory failure $(5.1 \%)$ then cardiogenic shock $(2.8 \%)$. The data are presented in (table 5)

Table 1. Socio-demographic data of the studied group (213 neonates):

\begin{tabular}{|c|c|c|}
\hline Variable & \multicolumn{2}{|c|}{$\begin{array}{l}\text { The studied group number (213) } \\
\text { mean } \pm \text { SD } \\
\text { (Range) } \\
\text { median }\end{array}$} \\
\hline $\begin{array}{c}\text { Gestational age } \\
\text { (weeks) }\end{array}$ & \multicolumn{2}{|c|}{$\begin{array}{c}35.3 \pm 2.7 \\
(28-40) \\
36\end{array}$} \\
\hline $\begin{array}{l}\text { Neonatal age at admission } \\
\text { (days) }\end{array}$ & \multicolumn{2}{|c|}{$\begin{array}{c}3.01 \pm 2.0 \\
(1-24) \\
1\end{array}$} \\
\hline $\begin{array}{l}\text { birth weight } \\
\text { (gm) }\end{array}$ & \multicolumn{2}{|c|}{$\begin{array}{c}2300 \pm 900 \\
(900-4100) \\
2200\end{array}$} \\
\hline Variable & Number(213) & $\%$ \\
\hline $\begin{array}{l}\text { Male } \\
\text { Female }\end{array}$ & $\begin{array}{l}110 \\
103\end{array}$ & $\begin{array}{l}51.6 \% \\
48.4 \%\end{array}$ \\
\hline Preterm $\quad(<37$ weeks $)$ & 119 & $55.9 \%$ \\
\hline ( $\geq 37$ weeks) & 94 & $44.1 \%$ \\
\hline$(<1000 \mathrm{gm})$ & 1 & $0.5 \%$ \\
\hline VLBW $\quad(1000-<1500 \mathrm{gm})$ & 31 & $14.6 \%$ \\
\hline LBW $\quad(1500-<2500 \mathrm{gm})$ & 90 & $42.3 \%$ \\
\hline Birth weight $\geq 2500 \mathrm{gm}$ & 91 & $42.7 \%$ \\
\hline
\end{tabular}


Table 2. Maternal history of the studied group:

\begin{tabular}{|c|c|c|}
\hline Variable & \multicolumn{2}{|c|}{$\begin{array}{c}\text { The studied group }(213) \\
\text { mean } \pm \text { SD } \\
\text { (Range) } \\
\text { median }\end{array}$} \\
\hline $\begin{array}{l}\text { Maternal age } \\
\text { (years): }\end{array}$ & \multicolumn{2}{|c|}{$\begin{array}{c}28.1 \pm 5.8 \\
(19-43) \\
27\end{array}$} \\
\hline Variable & Number (213) & $\%$ \\
\hline $\begin{array}{l} \\
\text { primigravida } \\
\text { para } 1 \\
\text { para } 2 \\
\text { para } 3 \\
\text { para } 4 \\
\text { para } 5\end{array}$ & $\begin{array}{l}53 \\
20 \\
44 \\
65 \\
21 \\
10\end{array}$ & $\begin{array}{c}24.9 \% \\
9.4 \% \\
20.7 \% \\
30.5 \% \\
9.9 \% \\
4.7 \% \\
\end{array}$ \\
\hline $\begin{array}{l}\text { No } \\
\text { Severe anemia }(\mathrm{Hb} \text { level }<7 \mathrm{gm} / \mathrm{dl}) \\
\text { D.M } \\
\text { SLE } \\
\text { Bronchial asthma } \\
\text { Hyperthyroidism } \\
\text { Hypothyroidism } \\
\text { ITP } \\
\text { Cardiac } \\
\text { Hemophilia } \\
\text { Others }\end{array}$ & $\begin{array}{c}163 \\
17 \\
7 \\
5 \\
5 \\
3 \\
3 \\
3 \\
2 \\
2 \\
3\end{array}$ & $\begin{array}{l}76.5 \% \\
8.0 \% \\
3.3 \% \\
2.3 \% \\
2.3 \% \\
1.4 \% \\
1.4 \% \\
1.4 \% \\
0.9 \% \\
0.9 \% \\
1.5 \%\end{array}$ \\
\hline $\begin{array}{l}\text { Maternal medications } \\
\text { No } \\
\text { Methyl dopa } \\
\text { Packed RBCs transfusion } \\
\text { Immunosuppressive drugs } \\
\text { Insulin } \\
\text { B2 agonist } \\
\text { Propylthiouracil } \\
\text { Thyroxin } \\
\text { Anti hemophilic factor replacement } \\
\text { Others }\end{array}$ & $\begin{array}{c}102 \\
62 \\
17 \\
8 \\
7 \\
5 \\
3 \\
3 \\
2 \\
4\end{array}$ & $\begin{array}{c}47.9 \% \\
29.1 \% \\
8.0 \% \\
3.80 \% \\
3.3 \% \\
2.35 \% \\
1.41 \% \\
1.41 \% \\
0.9 \% \\
1.9 \%\end{array}$ \\
\hline
\end{tabular}


Table 3. Perinatal history of the studied group:

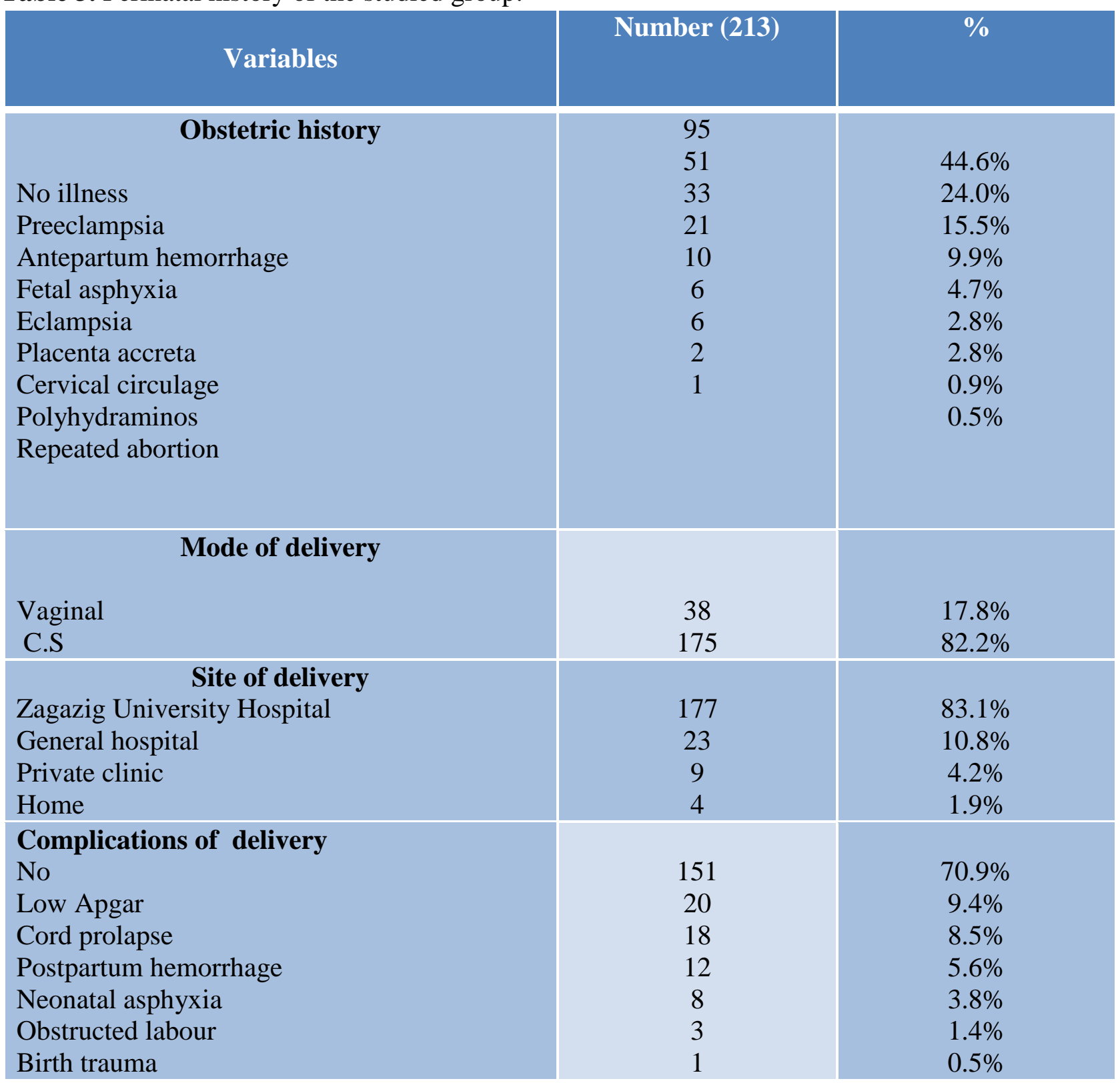


Table 4. Neonatal medications* during NICU admission and surgical history among the studied group:

\begin{tabular}{|c|c|c|}
\hline Variables & $\begin{array}{l}\text { Number } \\
\text { (213) }\end{array}$ & $\%$ \\
\hline Antibiotics & 213 & $100.0 \%$ \\
\hline Parenteral nutrition & 207 & $97.1 \%$ \\
\hline Positive inotropes & 64 & $30.1 \%$ \\
\hline Caffeine citrate & 61 & $28.6 \%$ \\
\hline Fluconazole & 25 & $11.7 \%$ \\
\hline Ibuprofen & 16 & $7.1 \%$ \\
\hline Frusemide & 15 & $7.04 \%$ \\
\hline Anticonvulsant & 11 & 5.2 \\
\hline Prostaglandin E1 & 9 & $4.2 \%$ \\
\hline LMWH** & 4 & $1.9 \%$ \\
\hline Regular NaHCO3 Infusion & 4 & $1.9 \%$ \\
\hline Therapeutic Vitamin K & 3 & $1.4 \%$ \\
\hline Acyclovir & 3 & $1.4 \%$ \\
\hline Sodium benzoate & 3 & $1.4 \%$ \\
\hline Captopril & 2 & $0.9 \%$ \\
\hline $\begin{array}{l}\text { Surgical history } \\
\text { - No history of surgery } \\
\text {-Abdominal surgery } \\
\text {-Abdomino-thoracic surgery } \\
\text {-Thoracic surgery(including intercostal tubes) } \\
\text {-Nasal surgery } \\
\text { - Neurosurgery }\end{array}$ & $\begin{array}{c}180 \\
21 \\
3 \\
6 \\
2 \\
1\end{array}$ & $\begin{array}{c}84.5 \% \\
9.9 \% \\
1.4 \% \\
2.8 \% \\
0.9 \% \\
0.5 \%\end{array}$ \\
\hline
\end{tabular}

*neonate might be given more than one drug during NICU admission.

** LMWH: low molecular weight heparin 
Table 5. Outcome and causes* of death among the studied group during NICU admission: -

\begin{tabular}{l|c|c}
\multicolumn{1}{c}{ Outcome of studied group } & Number (213) & \\
& & \\
& & \\
Discharged & 172 & $80.8 \%$ \\
Dead & 41 & $19.2 \%$ \\
\hline Causes of death in dead neonates & Number (41) & $\%$ \\
& & $63.41 \%$ \\
& 26 & $26.82 \%$ \\
Sepsis & 11 & $14.63 \%$ \\
Respiratory failure & 6 & $9.8 \%$ \\
Cardiogenic shock & 4 & $2.4 \%$ \\
Surgical complications & 3 & $2.4 \%$ \\
Severe respiratory distress syndrome & 1 & $2.4 \%$ \\
Severe hypoxic ischemic encephalopathy & 1 & \\
Hyperammonemia & 1 & \\
Severe metabolic acidosis & &
\end{tabular}

*neonate might have more than one cause of death. 
Figure 1. Flow Chart of the study:

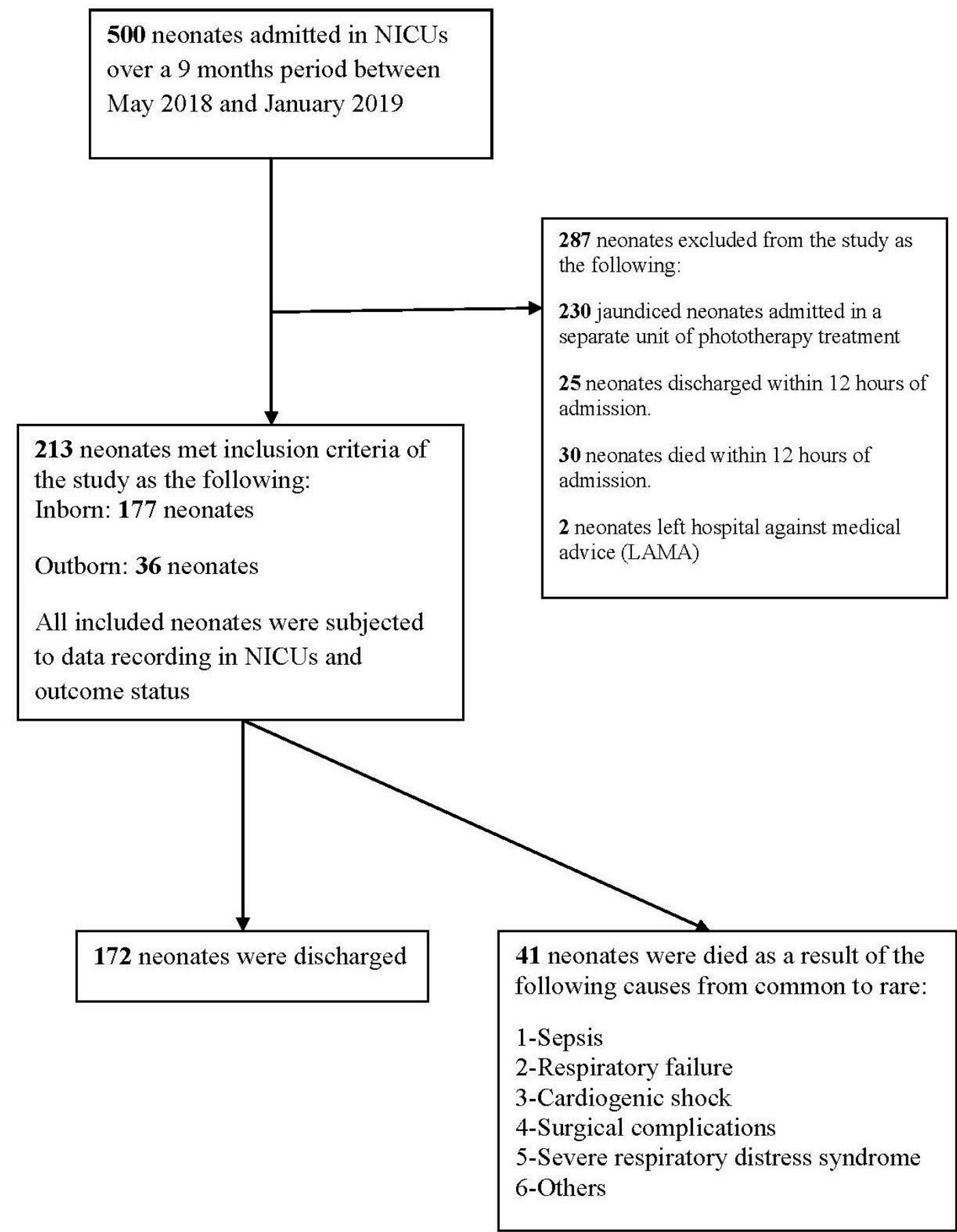


Figure 2. Primary diagnosis among preterm and full-term neonates admitted to NICU (213 neonates):

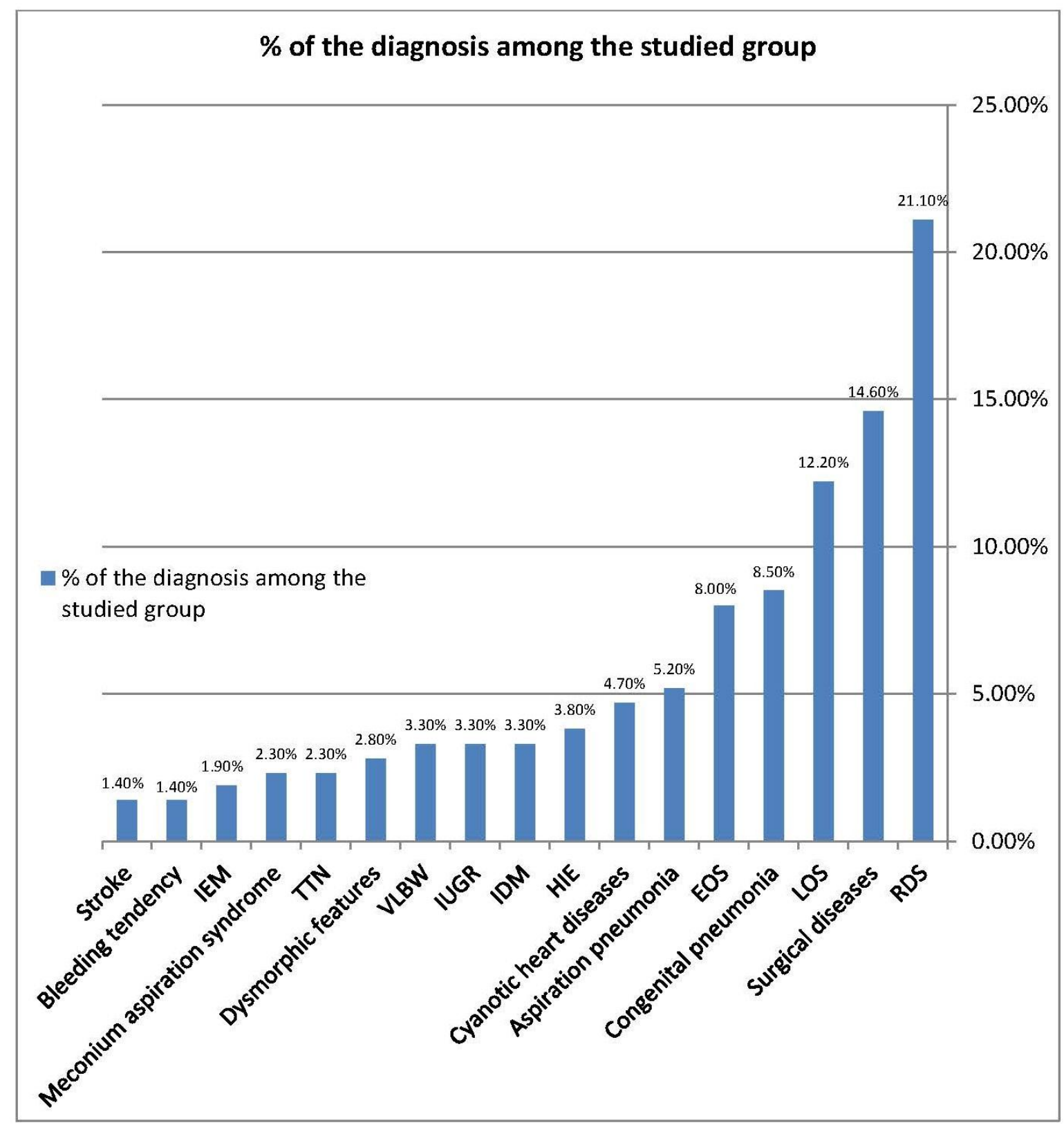

RDS: respiratory distress syndrome, LOS: late onset sepsis, HIE: hypoxic ischemic encephalopathy, IDM: infant of diabetic mother, IUGR: intrauterine growth restriction, VLBW: very low birth weight, TTN: transient tachypnea of newborn, IEM: inborn error of metabolism

\section{DISCUSSION}

Morbidity and mortality data obtained from regular registration are beneficial for health care providers and researchers to propose interventions for prevention, treatment and adjusting the quality of care. There is limited data and published reports in Egypt about NICUs care.

The results of this study showed that the mean of gestational age of the studied neonates was 
$(35.3 \pm 2.7)$ weeks and preterm neonates were $(55.9 \%)$ and term neonates were $(44.1 \%)$.

In a study conducted by Ferraresi (5) showed matched results, on the contrary, Tekleab et al., (2) showed that $(39.8 \%)$ were preterm and $(60.2 \%)$ were term.

The mean of neonatal age at admission in this study was (3.01 \pm 2.0$)$ days; it was matched with Farah et al., [6].

Males were $(51.6 \%)$ and female were $(48.4 \%)$ with male to female ratio was $(1.1 \%)$ in this study which is similar to study results of Sridhar et al. [7] and Hedstrom et al. [8]

The mean of birth weight of neonates of this study were $(2300 \pm 900 \mathrm{gm})$ and $(42.7 \%)$ of admitted neonates were $\geq 2500$ gm, $(42.3 \%)$ were LBW, $(14.6 \%)$ were VLBW and $(0.5 \%)$ were ELBW which was similar to study results of Bokade [9] and Rakholia, et al.[10] , on the contrary, Verma et al., [11] showed that; neonates with birth weight $\geq 2500 \mathrm{gm}$ were $(38.4 \%)$, LBW babies were $(54 \%)$, VLBW babies were (6\%), ELBW were $(1.2 \%)$.

The maternal age of the studied group ranged from (19 to 43) years, $(24.9 \%)$ were primigravida, that is similar to Hedstrom et al.[8], on the contrary, Ferraresi [5] showed that $(47.0 \%)$ were primigravida and a higher frequency was observed in the maternal age range of 26 to 30 years old $(28.0 \%)$ and 21 to 25 years old $(22.9 \%)$.

This study showed that inborn neonates were $(83.1 \%)$ and outborn were $(16.9 \%),(82.2 \%)$ of neonates were born by C.S.

Increased emergency C.S in this study matched with Egypt demographic and health survey (EDHS) 2014 [12] stated that overall $87 \%$ of all live births delivered in hospital and slightly more than half of births (52\%) were by C.S; this represented a sharp increase from 2008 when $28 \%$ of births were C.S, on the contrary,Tekleab et al. [2], Hedstrom et al.[8], Bokade [9] and Verma et al.,[11] showed different results as $40 \%, 11.66 \%$, $31.9 \%$ and $30.4 \%$ were born by C.S.respectively.

This may partially explained by increasing emergency C.S in tertiary obstetric hospital that receives high-risk pregnant women.

The commonest diagnosis during NICU admission in this study were $\operatorname{RDS}(21.1 \%)$ followed by surgical problems (14.6\%), late onset sepsis (12.2\%) then congenital pneumonia $(8.5 \%)$,similar results as Raikwar et al.[13], on the contrary, Sridhar et al, [7] stated that main causes of admission to NICU were sepsis (28.8\%), RDS (23.85\%), HIE(17.72\%), jaundice $(7.02 \%)$ and meconium aspiration syndrome $(5.47 \%)$.

All of the studied newborns received antibiotics that matched with a study conducted by Undela et al. [14] showed that approximately half of all medications prescribed to neonates were antimicrobials and $91 \%$ of neonates were prescribed as a minimum one antibiotic and Dhudasia et al. [15] stated that at least 100 neonates receive antibiotics for each one with early onset sepsis in NICU.

The results of this study showed that (15.5\%) of the studied group had surgical problems and abdominal surgery was the commonest surgery done for these neonates $(9.9 \%)$ followed by thoracic surgery (2.8\%).

Increased surgical problems admissions in this study explained by availability of neonatal surgical unit that considered as a referral unit for neonatal surgical problems.

The results of this study showed that (19.2\%) of the studied newborns were died, that were similar to results of studies conducted by Narayan [16] and Walana et al. [17], on the contrary, Raikwar et al. [13],Mohamed et al. [18],Narayan [19] and Abdel-Latif et al.[20] showed different mortality rate results $(36$, $6 \%, 58.8 \%, 8 \%, 8 \%$ ) respectively.

The results of this study were matched with other studies conducted in Egypt that showed, the rate of neonatal mortality among cases admitted to the NICUs in Benha university hospital and Tanta city hospitals were $(30.6 \%, 27.7 \%)$ of the studied neonates respectively. [21-22]

The commonest cause of death among our studied newborns was sepsis $(63.41 \%$ of dead neonates) followed by respiratory failure $(26.82 \%)$ then cardiogenic shock (14.63\%), that was matched with results of studies conducted by Muthukumaran [23], Sabzehei et al. [24] and Medhat $\mathrm{H}$ et al. [25].on the contrary,Vema et al.[11] and Raikwar et al.[13] whose stated that the commonest 
causes of death was prematurity with RDS then sepsis and perinatal asphyxia.[13]

High prevalence of neonates with mortality related to sepsis in this study due to high various manipulations that were done in NICUs that could lead to neonatal infections and neonatal surgical unit that considered as a referral unit for critically ill neonates with surgical diseases.

The strengths of this study include the systematic follow-up of neonates for hospitalization duration to fill a substantial significant gap in the understanding of all aspects of medical conditions, medication use and neonatal mortality in NICUs of university hospital of Zagazig.

This study has some limitations including that the sample was not a reflection of all births because high-risk and referred pregnancies are more likely to deliver in tertiary center, we do not realize if these data are representative of what happens in smaller NICUs and also being a cross sectional rather than a prospective randomized clinical trial study.

We recommend that larger multicenter studies evaluating disease patterns, medications given, resource utilization and outcomes of the neonates hospitalized in NICU.

\section{CONCLUSION}

The most common diagnosis during NICU admission was RDS then surgical diseases and sepsis. The antibiotics and parenteral nutrition were commonly prescribed medications in NICU. Sepsis was the main cause of newborn mortality. Data recording and analysis help in adjusting the quality of care.

Acknowledgement:

We show our gratitude for our patients and all families who participated in this study.

Conflict of interests: No conflict of interest. Financial disclosure: No financial disclosure.

\section{REFERENCES}

1-Harrison W, Goodman D. Epidemiologic trends in neonatal intensive care, 20072012. JAMA pediatrics. 2015 Sep 1; 169(9):855-62.

2-Tekleab AM, Amaru GM, Tefera YA. Reasons for admission and neonatal outcome in the neonatal care unit of a tertiary care hospital in Addis Ababa: a prospective study. Res Rep Neonatal. 2016; 6:17.

3- UNICEF/WHO/The World Bank/UN Pop Div. Levels and Trends in Child Mortality. Report 2014.

4- Lawn JE, Kinney MV, Black RE, Pitt C, Cousens S, Kerber $\mathrm{K}$, et al. Newborn survival: a multi-country analysis of a decade of change. Health Policy Plan.2012 Jun 7; 27(suppl_3): iii6-28.

5-Ferraresi MF, da Rocha Arrais A. Epidemiological profile of newborns' mothers admitted to a public neonatal unit. Rev Rene. 2016; 17(6):733-40.

6-Farah AE, Abbas AH, Ahmed AT. Trends of admission and predictors of neonatal mortality: A hospital based retrospective cohort study in Somali region of Ethiopia. PloS one. 2018 Sep 14; 13(9): e0203314.

7- Sridhar PV, Thammanna PS, Sandeep M. Morbidity pattern and hospital outcome of neonates admitted in a tertiary care teaching hospital, Mandya. Int J Sci Stud. 2015 Sep 1; 3(6):126-9.

8- Hedstrom A, Ryman T, Otai C, Nyonyintono J, McAdams RM, Lester D, et al. Demographics, clinical characteristics and neonatal outcomes in a rural Ugandan NICU. BMC pregnancy childbirth. 2014 Dec; 14(1):327.

9- Bokade CM, Meshram RM. Morbidity and mortality patterns among outborn referral neonates in central India: Prospective observational study. J Clin Neonatol. 2018 Jul 1; 7(3):130.

10- Rakholia R, Rawat V, Bano M, Singh G. Neonatal morbidity and mortality of sick newborns admitted in a teaching hospital of Uttarakhand. CHRISMED J Health Res .2014 Oct 1;1(4):228.

11- Verma J, Anand S, Kapoor N, Gedam S, Patel U. Neonatal outcome in newborns admitted in NICU of tertiary care hospital in central India: a 5-year study. Int J Contemp Pediatr. 2018 Jul; 5:1364-7.

12- Ministry of Health and Population, El-Zanaty and Associates, and ICF International. Egypt Demographic and Health Survey 2014. Cairo, Egypt and Rockville, Maryland, USA. 2015.

13- Raikwar P. A study of neonatal admission pattern and outcome from rural haryana. Glob J Res Anal. 2018 Feb; 19:12-6.

14- Undela K, Mohammed BT, Gurumurthy P, Doreswamy SM. Impact of preterm birth and 
low birth weight on medical conditions, medication use and mortality among neonates: a prospective observational cohort study. World J Pediatr . 2019:1-8.

15- Dhudasia MB, Mukhopadhyay S, Puopolo KM. Implementation of the sepsis risk calculator at an academic birth hospital. Hosp Pediatr. 2018 May 1; 8(5):243-50.

16- Narayan R, Singh S. A study of pattern of admission and outcome in a neonatal intensive care unit at Rural Haryana, India. Int J Pediatr Res. 2017; 4(10):611-616.

17- Walana W, Acquah Ekuban KS, AbdulMumin A, Naafu B, Aruk E. Pattern, Causes and Treatment Outcomes of Neonatal Admission in the Tamale Teaching Hospital. Clinics Mother Child Health. 2016; 13(252):2.

18-Mohamed EM, Soliman AM, El-Asheer OM. Predictors of mortality among neonates admitted to neonatal intensive care unit in pediatric Assiut University Hospital, Egypt. J Am Sci. 2011; 7(6):606-11.

19- Narayan R. A study of the pattern of admissions and outcome in a neonatal intensive care unit at high altitude. Sri Lanka Journal of Child Health. 2012 Jun 11; 41(2).

20- Abdel-Latif ME, Nowak G, Bajuk B, Glass K, Harley D. Variation in hospital mortality in an Australian neonatal intensive care unit network. Arch Dis Child Fetal Neonatal Ed. 2018 Jul 1; 103(4): F331-6.

21-Abdel Hady S, Haie O, Eldesouky R, Gabal $M$. Incidence and the underlying factors of neonatal mortality in the university hospital of Benha, Egypt. Int J Med Health Sci. (2016) 5 (4): 237-244.

22-El-Ganainy HF, El-Mashad AE, Shihab NS, Abu-Hamama AM. Risk Factors for Neonatal Mortality in Neonatal Intensive Care Units in Tanta City. ejhm. 2019 Apr 1; 75(1):19962006.

23- Muthukumaran N. Mortality profile of neonatal deaths and deaths due to neonatal sepsis in a tertiary care center in southern India: a retrospective study. Int $\mathrm{J}$ Contemp Pediatr. 2018 Jul; 5(4):1583.

24- Sabzehei MK, Basiri B, Shokouhi M, Eghbalian F, Eslamian MH. Causes and risk factors associated to neonatal mortality in Neonatal Intensive Care Unit (NICU) in Besat Hospital Hamadan-Iran in 2015 to 2016. Int J Pediatr. 2018 Sep 1;6(9):8185-94.

25- Medhat H, Khashana A. Incidence of Neonatal Infection in South Sinai, Egypt. Int J Infect. 2017; 4(1). 